\title{
Regulation of protein translation initiation in response to ionizing radiation
}

\author{
Donatella Trivigno', Laura Bornes ${ }^{2}$, Stephan M Huber ${ }^{1}$ and Justine Rudner ${ }^{1,2^{*}}$
}

\begin{abstract}
Background: Proliferating tumor cells require continuous protein synthesis. De novo synthesis of most proteins is regulated through cap-dependent translation. Cellular stress such as ionizing radiation (IR) blocks cap-dependent translation resulting in shut-down of global protein translation which saves resources and energy needed for the stress response. At the same time, levels of proteins required for stress response are maintained or even increased. The study aimed to analyze the regulation of signaling pathways controlling protein translation in response to IR and the impact on Mcl-1, an anti-apoptotic and radioprotective protein, which levels rapidly decline upon IR.

Methods: Protein levels and processing were analyzed by Western blot. The assembly of the translational preinitiation complex was examined by Immunoprecipitation and pull-down experiments with 7-methyl GTP agarose. To analyze IR-induced cell death, dissipation of the mitochondrial membrane potential and DNA fragmentation were determined by flow cytometry. Protein levels of the different initiation factors were down-regulated using RNA interference approach.

Results: IR induced caspase-dependent cleavage of the translational initiation factors elF4G1, elF3A, and elF4B resulting in disassembly of the cap-dependent initiation complex. In addition, DAP5-dependent initiation complex that regulates IRES-dependent translation was disassembled in response to IR. Moreover, IR resulted in dephosphorylation of 4EBP1, an inhibitor of cap-dependent translation upstream of caspase activation. However, knock-down of elF4G1, elF4B, DAP5, or 4EBP1 did not affect IR-induced decline of the anti-apoptotic protein Mcl-1.

Conclusion: Our data shows that cap-dependent translation is regulated at several levels in response to IR. However, the experiments indicate that IR-induced Mcl-1 decline is not a consequence of translational inhibition in Jurkat cells.
\end{abstract}

Keywords: lonizing radiation, Protein translation, Eukaryotic initiation factor, Akt, mTOR, Apoptosis, Mcl-1

\section{Background}

Cells need to replenish their protein pools of with every cell division. Therefore, protein synthesis is considerably up-regulated in proliferating tumor cells. The rate limiting step during protein synthesis is the initiation of translation which is regulated by several initiation factors (IF). They allow the recruitment of the initiator tRNA and mRNA to the $40 \mathrm{~S}$ ribosomal subunit, recognition of the start codon AUG, and joining of the $40 \mathrm{~S}$ and $60 \mathrm{~S}$ ribosomal subunits leading to the formation of peptid bonds during protein elongation. The eucaryotic initiation factors eIF3, eIF4A,

\footnotetext{
* Correspondence: justine.rudner@uk-essen.de

* Correspondence: justine.rudner@uk-essen.de
'Department of Radiation Oncology, University Hospital of Tuebingen, Hoppe-Seyler-Str. 3, 72076, Tübingen, Germany

${ }^{2}$ Institute for Cell Biology, University Hospital Essen, Virchowstr. 173, 45147, Essen, Germany
}

eIF4B, eIF4E, eIF4G1, eIF4H, and the poly A-binding protein (PABP) regulate the recruitment of mRNA to the initiation complex. eIF4E recognizes the 7-methyl GTP structure (cap structure) at the 5' end of mRNA while PABP binds to the 3' end of the mRNA. The helicase eIF4A, helped by eIF4B and eIF4H, unwinds the secondary mRNA structure at the $5^{\prime}$ end. The initiation factor eIF3, a multimeric complex of 13 different polypeptids (named eIF3A-M), interacts with the $43 \mathrm{~S}$ ribosomal subunit that consist of $40 \mathrm{~S}$ ribosomal subunit and the initiation factor eIF2 loaded with the initiator tRNA. Binding directly to the initiation factors eIF3, eIF4A, eIF4E, and to PABP, the scaffolding protein eIF-4G1/p220 coordinates the recruitment of the different factors into the initiation complex [1]. 
The formation of the initiation complex and the initiation of translation are further regulated by different signalling pathways which sense the optimal environmental growth conditions. Activation of the protein kinase $\mathrm{B}$ (PKB)/Akt pathway results in phosphorylation and activation of the mammalian target of rapamycin (mTOR). On the one hand, the protein kinase mTOR activates ribosomal protein S6 kinase (p70S6K) whose substrate is S6, a subunit of ribosomes [2]. When phosphorylated, S6 increases the translation of a subset of mRNAs that encode ribosomal proteins. On the other hand, mTOR controls cap-dependent translation through the translational inhibitor eIF4E-binding protein 1 (4EBP1). Upon phosphorylation by mTOR, 4EBP1 is not able to interact with eIF4E. Suboptimal growth conditions and environmental stress lead to inactivation of mTOR, dephosphorylation of 4EBP1 and an increased association of 4EBP1 with eIF4E preventing eIF4E from binding to eIF4G [3].

A quick shut down of global protein translation is important in response to cellular damage and environmental stress. It allows the cell to save resources and energy that is needed to repair the cellular defects. At the same time, it is important to maintain or even increase levels of proteins required for repair [4]. For this purpose, the cell can switch to cap-independent translation bypassing the capdependent translational inhibition. Around 10\% of mRNAs contain an internal ribosome entry site (IRES) which allows a continuing translation of respective proteins under stress conditions [5]. IRES-dependent translation can be mediated by death associated protein 5 (DAP5 or p97), also known as eIF4G2 due to its homology to eIF4G1. In contrast to eIF4G1, DAP5 does not interact with eIF4E, but still binds to eIF3A and eIF4A. DAP5-dependent translational activity can be enhanced by caspase-dependent cleavage of DAP5 during apoptosis [6].

To secure survival under such unfavorable conditions, the cell must also maintain levels of protecting proteins. Myeloid cell leukemia sequence 1 (Mcl-1) belongs to the anti-apoptotic proteins of the $\mathrm{Bcl}-2$ family that prevent apoptosis induction in response to many stress stimuli. Similar to the homologous proteins Bcl-2 and Bcl-xL, Mcl1 is over-expressed in many tumors and associated with resistance to anti-neoplastic therapies such as ionizing radiation (IR). In many tumor cells, down-regulation of Mcl1 is sufficient to induce apoptosis $[7,8]$. In contrast to Bcl-2 and Bcl-xL, Mcl-1 is an instable protein with a short half life time. Shut down of protein translation results in a rapid Mcl-1 decline and apoptosis induction $[9,10]$.

So far, it has not yet been investigated whether radiation-induced down-regulation of the short-lived Mcl-1 is linked to inhibition of translation. Using Jurkat $\mathrm{T}$ lymphoma cells as a cell model, we examined protein translation and Mcl-1 levels in response to IR. Here, we could show that cap-dependent as well as cap-independent but DAP5-dependent translation were reduced after irradiation. Mcl-1 protein levels were regulated by an eIF4G1-dependent mechanism. However, RNAi knockdown of 4EBP1, eIF4B, eIF4G1, or DAP5 showed that neither cap-dependent nor DAP5-dependent translation affected radiation-induced Mcl-1 decline.

\section{Material and methods}

\section{Inhibitors and antibodies}

Pan-caspase inhibitor zVAD-fmk was purchased from Bachem (Bubendorf, Suisse), LY294002 was obtained from Cell Signaling (NEB, Frankfurt, Germany).

Following antibodies were used for Western blotting and immunoprecipitation: mouse-anti $\beta$-actin from Sigma (Deisenhofen, Germany), mouse-anti GAPDH from Abcam (Cambridge, UK), rabbit-anti Akt, phospho-Akt (S473), phospho-Akt (T308), mTOR, phospho-mTOR (S2448), phospho-mTOR (S2481), S6K, phospho-S6K (T389), 4EBP1, phospho-4EBP1 (T37/46), phospho-4EBP1 (T70), Mcl-1, eIF3A, eIF4A, eIF4B, eIF4E, eIF4G, phospho-eIF4G, and DAP5 from Cell Signaling (NEB, Frankfurt, Germany).

\section{Cells and cell culture}

Jurkat E6 T-lymphoma cells were obtained from ATCC (Bethesda, Maryland, USA). Cells were grown in RPMI 1640 medium supplemented with $10 \%$ fetal calf serum (Gibco Life Technologies, Eggenstein, Germany) and maintained in a humidified incubator at $37^{\circ} \mathrm{C}$ and $5 \% \mathrm{CO}_{2}$.

\section{Transfection with siRNA}

Cells were cultured at a low density to ensure log phase growth. For transfection $3 \times 10^{6}$ cells were resuspended in $300 \mu \mathrm{L}$ RPMI-1640 without phenol red. Shortly before transfection, 4ebp1, eif4b, eif4g1, dap5, or non-targeting siRNA was added at indicated concentrations. The respective siRNA ON-TARGET SMARTpools and the siCONTROL NON-TARGETING pool siRNA were purchased from Dharmacon (Chicago, IL, USA). Cells were electroporated in a $4 \mathrm{~mm}$ cuvette in an EPI2500 square pulse electroporator (Fischer, Heidelberg, Germany) at $370 \mathrm{~V}$ for 9 msec. Immediately after transfection cells were resuspended in $6 \mathrm{~mL}$ pre-warmed medium and continued to be cultured as described above.

\section{Flow cytometric analysis}

The mitochondrial membrane potential $(\Delta \Psi \mathrm{m})$ was analyzed using the $\Delta \Psi \mathrm{m}$ specific dye TMRE (Molecular Probes, Mobitech, Goettingen, Germany). At the indicated time points, cells were stained for $30 \mathrm{~min}$ in PBS containing $25 \mathrm{nM}$ TMRE. To measure DNA fragmentation, cells were incubated with PBS containing 0.1\% Triton X-100 and $10 \mu \mathrm{g} / \mathrm{ml}$ propidium iodide. Cells were detected in channel 2 (488 nM excitation, 564-606 nm emission) employing a FACS Calibur flow cytometer 
(Becton Dickinson, Heidelberg, Germany) and analyzed with the FCS Express 3 software (De Novo Software, Los Angeles, CA, USA). Data show mean values +/- S.D. of 3 independent experiments. Statistical significance was calculated by a one-way ANOVA test using GraphPad Software (San Diego, CA, USA).

\section{Western blot analysis}

Cells were lysed in $200 \mu \mathrm{L}$ lysis buffer containing $50 \mathrm{mM}$ HEPES pH 7.5, $150 \mathrm{mM} \mathrm{NaCl}, 1 \%$ Triton X-100, $1 \mathrm{mM}$ EDTA, $10 \mathrm{mM}$ sodium pyrophosphate, $10 \mathrm{mM} \mathrm{NaF}, 2$ $\mathrm{mM} \mathrm{Na} \mathrm{VO}_{4}, 100 \mathrm{mM}$ PMSF, $5 \mu \mathrm{g} / \mathrm{ml}$ Aprotinin, $5 \mu \mathrm{g} / \mathrm{ml}$ Leupeptin, and $3 \mu \mathrm{g} / \mathrm{ml}$ Pepstatin as described before [11]. Protein was separated by SDS-PAGE and transferred onto PVDF membranes (Roth, Karlsruhe, Germany). Membranes were blocked in TBS buffer containing 0.05\% Tween 20 and $5 \%$ non-fat dry milk for $1 \mathrm{~h}$ at room temperature. The membrane was incubated overnight at $4{ }^{\circ} \mathrm{C}$ with the respective primary antibodies. After repeated washings with TBS/Tween-20 (0.05\%) the membranes were incubated with the secondary antibody for $1 \mathrm{~h}$ at room temperature before continuing to wash with TBS/Tween-20 (0.05\%). Antibody binding was detected by enhanced chemoluminescence (ECL Western blotting analysis system, GE Healthcare/Amersham-Biosciences, Freiburg, Germany). Equal loading was verified by antibodies against $\beta$-actin or GAPDH. Where indicated protein levels were quantified by densitometry using ImageJ software (ImageJ $1.40 \mathrm{~g}$ $\mathrm{NIH}$, USA). All Western blot experiments were repeated at least once.

\section{Cap pulldown}

Cells were lysed as described for "Western blot analysis". $60 \mu \mathrm{L}$ of 7 -methyl GTP-sepharose ${ }^{\mathrm{TM}} 4 \mathrm{~B}$ beads (GE Healthcare/Amersham-Biosciences, Freiburg, Germany) were incubated with $250 \mu \mathrm{g}$ of protein in $500 \mu \mathrm{l}$ lysis buffer for $2 \mathrm{~h}$ at $4^{\circ} \mathrm{C}$. Beads were washed trice with $500 \mu \mathrm{l}$ lysis buffer. Proteins were eluted by boiling the beads for $5 \mathrm{~min}$ in $100 \mu \mathrm{L}$ SDS sample buffer containing $2.5 \%$ $\beta$-mercaptoethanol. $30 \mu \mathrm{L}$ were separated by SDS gel electrophoresis.

\section{Immunoprecipitation}

Cells were lysed as described for "Western blot analysis" using 1\% CHAPS instead of Triton X-100. The protein concentration was adjusted to $2 \mathrm{mg} / \mathrm{mL}$. 1-2 $\mu \mathrm{g}$ antibody and $50 \mu \mathrm{L}$ slurry Dynabeads ${ }^{\circledR}$ suspension (Invitrogen, Karlsruhe, Germany) were added to $750 \mu \mathrm{L}$ lysate. After the precipitation for $3 \mathrm{~h}$ at $4^{\circ} \mathrm{C}$ the beads were washed thrice with $300 \mu \mathrm{L}$ lysis buffer containing $0.2 \%$ of the respective detergent. Proteins were eluted by boiling the beads for $5 \mathrm{~min}$ in $100 \mu \mathrm{L}$ SDS sample buffer with $\beta$-mercaptoethanol. $30 \mu \mathrm{L}$ were separated by SDS gel electrophoresis.

\section{Results}

To analyze cap-dependent protein translation in response to IR, Jurkat T lymphoma cells were irradiated with $10 \mathrm{~Gy}$. At indicated time, lysates were made and analyzed by Western blotting (Figure 1A). Caspase-3 and the known caspase-3 substrate, poly-(ADP-ribose) polymerase (PARP), were cleaved as early as $8 \mathrm{~h}$ after irradiation indicating the activation of the executioner caspase-3. While protein levels of eIF4A, eIF4E, and eIF4H did not change within $24 \mathrm{~h}$ after irradiation, cleavage of eIF4G1 and eIF3A was observed $12 \mathrm{~h}$ after irradiation. In addition, a continuous decline of eIF4B and the anti-apoptotic protein Mcl-1 was detected in response to irradiation.

The post-translational modifications of the initiation factors were correlated with disassembly of the initiation complex (Figure 1B). Using 7-methy-GTP agarose that imitates the cap structure in a pull-down assay, we could show that less eIF4G1, eIF4A, and eIF3A associated in the cap-binding initiation complex $24 \mathrm{~h}$ after irradiation. In addition, dephosphorylation of eIF4G was observed $24 \mathrm{~h}$ after IR (Figure 1A). Decreased eIF4G phosphorylation correlated with less eIF4G binding to 7-methyl -GTP-recognizing complex (Figure 1B).

Caspase-3 and PARP were processed with kinetics similar to those of the initiation factors suggesting a correlation between caspase activation and cleavage of initiation factors (Figure 1A). To examine whether the cleavage of initiation factors was caspase-dependent, cells were treated with $30 \mu \mathrm{M}$ pan-caspase inhibitor zVAD shortly before irradiation (Figure 1C). Western blots show caspase-3 (C3) and PARP processing that was inhibited by zVAD. Cleavage of eIF4G1, eIF3A, and eIF4B decline were also prevented by the caspase inhibitor suggesting that cleavage of eIF4G1 and eIF3A as well as eIF4B decline occurred after caspase activation. In contrast, radiation-induced 4EBP1 dephosphorylation and Mcl-1 decline were not inhibited by zVAD indicating a regulation independent of caspases. So far, our data suggest that the irradiation induced caspasedependent cleavage of the initiation factors eIF4G1, eIF3A, and eIF4B, coinciding with a disassembly of the capdependent translation initiation complex.

During radiation-induced apoptosis, a switch from capdependent to a cap-independent, but DAP5-dependent translation might occur. The DAP5-dependent translation is enhanced by proteolytic cleavage [12]. Indeed, cleavage fragment of DAP5 was detected in irradiated Jurkat (Figure 2A). DAP5 cleavage depended on caspase activation since treatment with caspase inhibitor zVAD prevented DAP5 processing (Figure 2B). DAP5 cannot interact with eIF4E and, therefore, was not detected in 7-methyl GTPagarose pull-down experiments (Figure 2C). Similar to eIF4G1, DAP5 can interact with eIF3A and eIF4A [12]. We wanted to know whether there was a switch from capdependent, eIF4G1-dependent translation to a cap- 


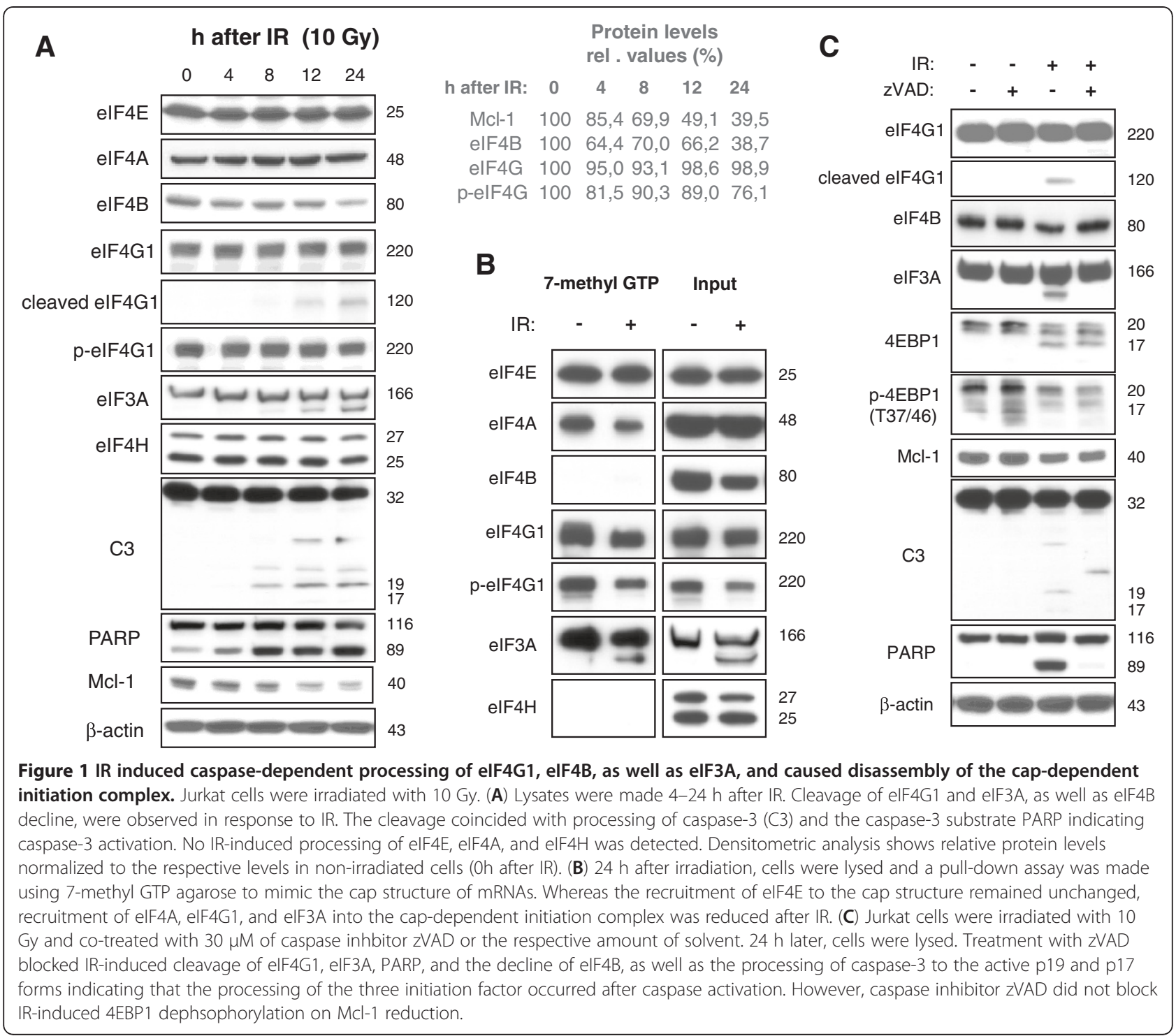

independent, DAP5-dependent translation after irradiation. Such a switch would imply that the initiation factors eIF3 and eIF4A showed a decreased association with eIF4G1, but an increased association with DAP5. However, immunoprecipitation experiments revealed that eIF3A and eIF4A showed a reduced affinity to DAP5 (Figure 2D) and to eIF4G1 (Figure 2E) in response to irradiation indicating that both, eIF4G1-dependent and DAP5-dependent translation, were reduced upon IR.

To test the effect of translational inhibition on the short-lived Mcl-1, the translational inhibitor cycloheximide (CHX, $1 \mu \mathrm{M})$ was added to cell culture of nonirradiated cells or irradiated cells $24 \mathrm{~h}$ after irradiation with $10 \mathrm{~Gy}$. Lysates were made $0 \mathrm{~min}, 30 \mathrm{~min}, 60 \mathrm{~min}, 90$ min, and $120 \mathrm{~min}$ after adding $\mathrm{CHX}$. Analysis of Mcl-1 protein levels showed a rapid decline of Mcl-1 following translational inhibition (Figure 3). Mcl-1 decline was faster in irradiated $\left(\mathrm{t}_{1 / 2}=34.9 \pm 2.5 \mathrm{~min}\right)$ than in non-irradiated $\left(t_{1 / 2}=69.6 \pm 11.7 \mathrm{~min}\right)$ cells. To further analyze the putative role of cap-dependent and DAP5-dependent protein translation of Mcl-1 during radiation-induced apoptosis, eIF4G1 and DAP5 were down-regulated by siRNA. Western blot analysis showed that both proteins were successfully silenced $48 \mathrm{~h}$ after electroporation (Figure 4A). Silencing of eIF4G1, but not DAP5, resulted in a reduction of Mcl-1 protein levels indicating that eIF4G1-dependent translation rather than the DAP5-dependent translation regulated Mcl-1 translation in healthy Jurkat cells. However, radiation-induced $\mathrm{Mcl}$-1decline was not affected by eIF4G1 and DAP5 siRNA (Figure 4B). In addition, flow cytometric analysis revealed that silencing of either eIF4G1 or DAP5 was not sufficient to significantly enhance $\Delta \Psi \mathrm{m}$ dissipation (Figure 4C) and DNA fragmentation (Figure 4D). Only when both proteins were simultaneously down-regulated, a 


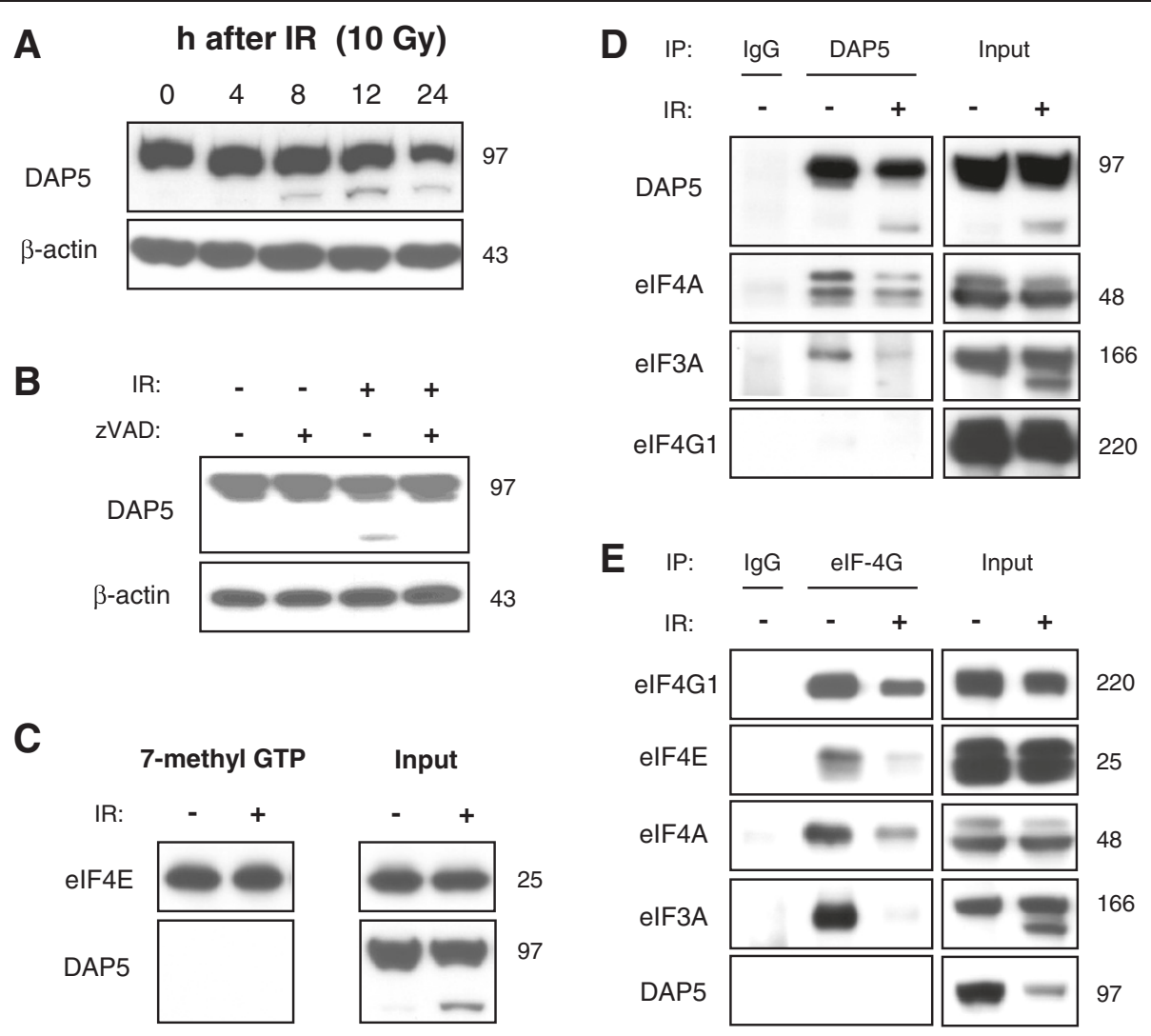

Figure 2 IR induced disassembly of the elF4G1-dependent as well as DAP5-dependent initiation complex. Jurkat cells were irradiated with $10 \mathrm{~Gy}$. (A) Lysates were made 4-24 h after IR. Cleavage of DAP5 was detected already $8 \mathrm{~h}$ after irradiation. (B) Jurkat cells were irradiated with $10 \mathrm{~Gy}$ and treated with $30 \mu \mathrm{M}$ of caspase inhbitor ZVAD or the respective amount of solvent. $24 \mathrm{~h}$ after irradiation, cells were lysed.

Treatment with zVAD abrogated IR-induced cleavage of DAP5. (C) $24 \mathrm{~h}$ after IR with $10 \mathrm{~Gy}$, cells were lysed and a pull-down assay was made using 7-methyl GTP agarose. DAP5 was not detected in the cap-dependent initiation complex. $24 \mathrm{~h}$ after IR with 10 Gy, cells were lysed and

DAP5 (D), and elF4G1 (E) were precipitated. (D) Less elF4A and elF3A co-precipitated with DAP5 (D) and elF4G1 (E) after IR indicating disassembly of the DAP5-dependent and elF4G1-dependent initiation complexes.

slight, but significant, increase of IR-induced $\Delta \Psi \mathrm{m}$ dissipation and DNA fragmentation was observed. Our data suggests that eIF4G1-dependent translation regulated Mcl-1 protein levels, but the IR-induced down-regulation of Mcl1 protein levels was independent of eIF4G1- or DAP5dependent translation. In response to IR, eIF4B protein level was down-regulated in Jurkat cells. To test the involvement in IR-induced apoptosis, the initiation factor eIF4B was silenced by RNA interference (Figure 5). Silencing of eIF4B neither affected Mcl-1 decline (Figure 5A), nor $\Delta \Psi \mathrm{m}$ dissipation (Figure $5 \mathrm{~B}$ ), nor DNA fragmentation (Figure $5 \mathrm{C}$ ) in response to irradiation suggesting that eIF4B was irrelevant for the regulation of Mcl-1 levels in response to irradiation.

Further analysis of protein translation focused on signal transduction through the kinases Akt and mTOR. The Akt/mTOR pathway controls protein translation through activation of p70S6K and inactivation of the translational inhibitor 4EBP1. Abrogation of this pathway should result in translational inhibition and a quick down-regulation of the instable Mcl-1. To this end, Jurkat T lymphoma cells were incubated with the PI3K inhibitor LY294002 (50$100 \mu \mathrm{M}$ for $6 \mathrm{~h}$; Figure 6A). Western blot analysis showed that LY294002 reduced phospho-Akt and phosphomTOR levels indicating an inhibition of both, Akt and mTOR. The mTOR substrates p70S6K and 4EBP1 were also dephosphorylated upon treatment with LY294002, indicating p70S6K inactivation and activation of 4EBP1. In addition, LY294002 reduced Mcl-1 levels and induced mitochondrial dissipation (Figure 6C) as well as DNA fragmentation (Figure 6D) in a concentration- and timedependent manner. Together, the results strongly suggest that Mcl-1 protein levels and Jurkat cells survival were controlled by the Akt/mTOR pathway. To examine the regulation of protein translation in response to IR, cells were irradiated with $10 \mathrm{~Gy}$. Lysates were made $4-24 \mathrm{~h}$ later (Figure 6B). In contrast to LY294002, irradiation affected neither phospho-Akt nor phospho-mTOR, nor phospho-p70S6K. Apart from Akt, the kinases ERK1/2 were suggested to control protein translation through S6K 


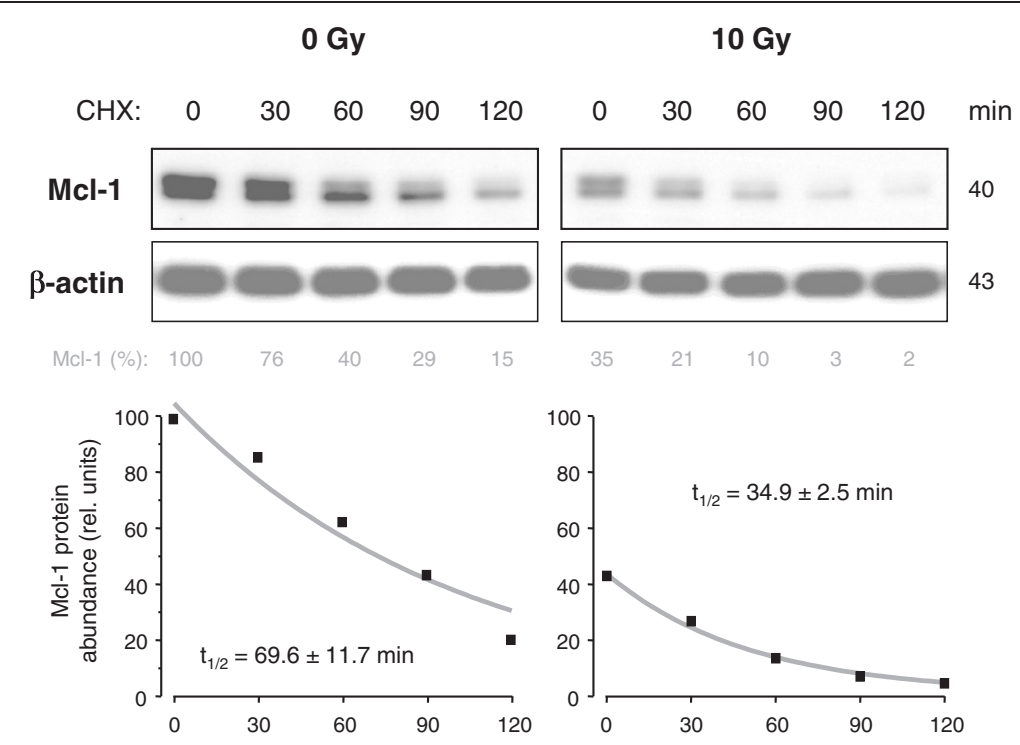

Figure 3 Inhibition of protein translation results in rapid Mcl-1 decline. Non-irradiated or, alternatively, 24 h after IR with 10 Gy, Jurkat cells were treated with $1 \mu \mathrm{M}(\mathrm{CHX})$ for 0-120 min. Cells were lysed at respective time points. Mcl-1 levels were analyzed by Western blot (upper panel). Mcl-1 levels were quantified by densitometry and normalized to the Mcl-1 level of untreated non-irradiated control cells. The values were fitted and the half-life of Mcl-1 was calculated (lower panel).

phosphorylation [13]. Phosphorylated ERK1/2 indicates kinase activity. Phospho-ERK1/2 levels were not changed in response to irradiation (Figure 6E) suggesting a contributory regulation of ribosomal translation by ERK1/2. In contrast, 4EBP1 was dephosphorylated in a time-dependent manner in response to IR. Concurrent with 4EBP1 dephosphorylation, Mcl-1 was down-regulated (Figure 6B). Furthermore, co-precipitation (Figure 7A) and pull-down experiments (Figure 7B) showed an increased association of 4EBP1 with cap-binding eIF4E. The results implicate a radiation-induced inhibition of cap-dependent translation which was independent of the Akt/mTOR and ERK1/2 pathways.

To analyze the extent of 4EBP1 on protein translation, especially on Mcl-1 translation, Jurkat cells were transfected with 4EBP1-targeting (4ebp1) or non-targeting (nt) siRNA. $48 \mathrm{~h}$ after transfection, cells were irradiated with 10 Gy and lysates were made 24 h post-irradiation. Down-regulation of 4EBP1 was verified by Western blot (Figure 7C). Dissipation of mitochondrial membrane potential $(\Delta \Psi \mathrm{m}$ low, Figure $7 \mathrm{D})$ and DNA fragmentation (sub G1, Figure 7E) were analyzed $24 \mathrm{~h}$ or $48 \mathrm{~h}$ after irradiation, respectively. In cells with low 4EBP1 levels, we expected an impaired translational inhibition and, therefore, a stabilization of Mcl-1 in response to IR. The failure to down-regulate Mcl-1 should have increased radioresistance and decreased radiation-induced apoptosis. However, 4EBP1 knock-down neither affected Mcl-1 levels (Figure $7 \mathrm{C}$ ) nor radiation-induced $\Delta \Psi \mathrm{m}$ dissipation (Figure 7D) and DNA fragmentation (Figure 7E). Thus, the decline of Mcl-1 did not depend on cap-dependent translational inhibition. Notably, transfection with siRNA targeting Mcl-1 (mcl1) caused a rapid loss of Mcl-1 3-6 h after electroporation that coincided with 4EBP1 dephosphorylation as detected by the shift from $20 \mathrm{kDa}$ to 17 $\mathrm{kDa}$ in Western blot (Figure 7F). This result indicates that the dephosphorylation of 4EBP1 could occur after depletion of Mcl-1 levels.

\section{Discussion}

Protein translation is frequently deregulated in tumor cells and accelerates tumorigenesis $[14,15]$. Many translational components are over-expressed in tumor cells. High levels of several eIF3 subunits were associated with malignant transformation, whereas eIF4B was connected to proliferation and survival $[16,17]$. Moreover, overexpression of eIF3A resulted in decreased sensitivity to cisplatin [18] whereas overexpression of eIF4G1 increased survival in irradiated breast cancer cells [19] indicating that individual components of the translational machinery might regulate cell survival in response to DNA damage induced by drugs or IR. Jurkat $\mathrm{T}$ lymphoma cells activated caspases in response to IR which resulted in the cleavage of several translational components, among others eIF4G1, eIF4B, and eIF3A. Proteolytic cleavage of eIF4G1 and eIF4B by caspase-3 during apoptosis induction was observed earlier [20,21]. Although caspasedependent cleavage of eIF3A has not been described yet, another component of the initiation factor eIF3, eIF3j, is a known caspase-3 substrate [22,23]. Evidently, caspase-3 -mediated cleavage of translation initiation factors is a general mechanism during apoptosis. 


\section{B-Actin blot \\ Densitometric analysis}

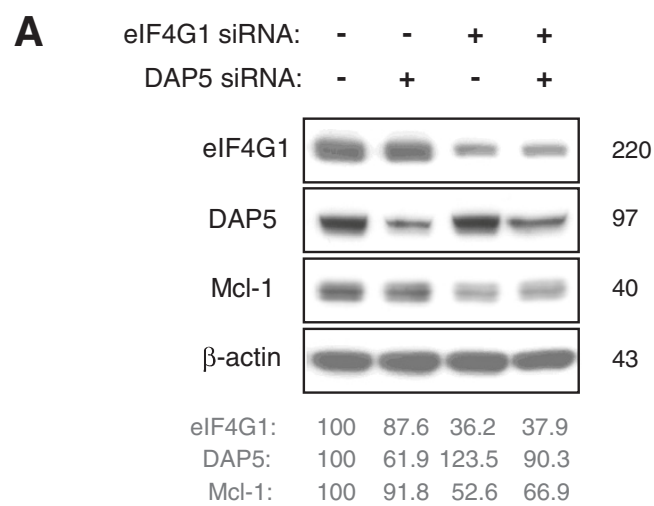

B

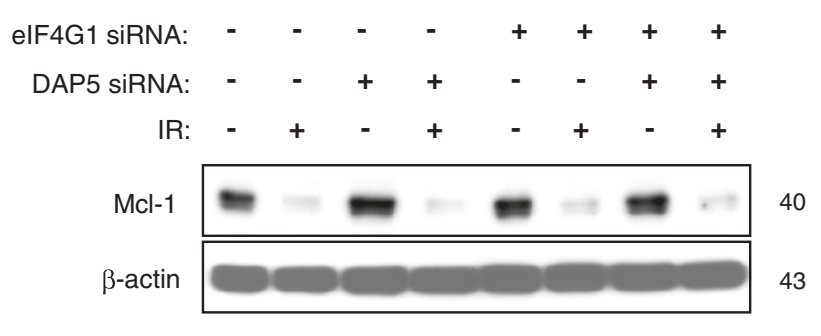

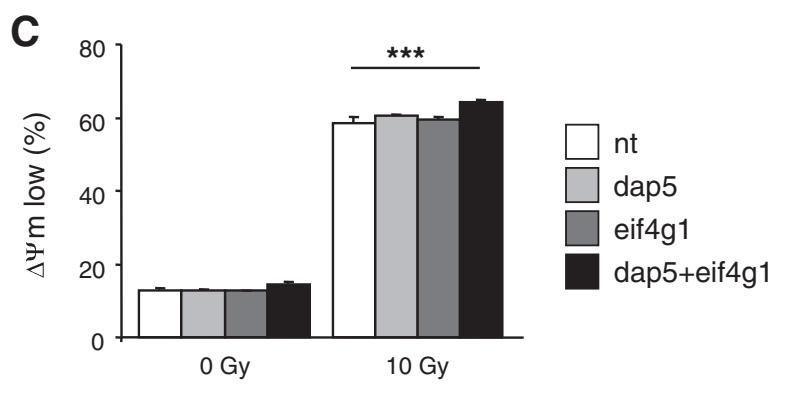

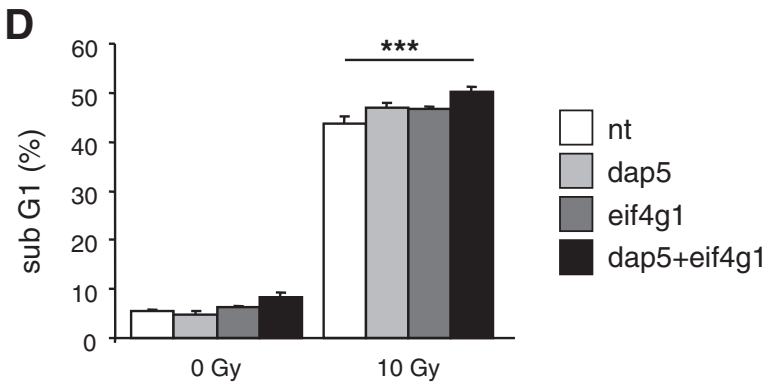

Figure 4 Combined silencing of elF4G1 and DAP5 accelerated radiation-induced apoptosis. Jurkat cells were transfected with $500 \mathrm{nM}$ eif4g1 siRNA or $500 \mathrm{nM}$ dap5 siRNA alone, or with both, $500 \mathrm{nM}$ eif4g1 and $500 \mathrm{nM}$ dap5 siRNA. $1 \mu \mathrm{M}$ non-targeting (nt) siRNA was electroporated into control cells. (A) $48 \mathrm{~h}$ later, cells were lysed and analyzed by Western blot. Protein levels were analyzed by densitometry and normalized to the respective levels in control cells transfected with non-targeting siRNA. Silencing of elF4G1 resulted in Mcl-1 decrease suggesting that Mcl-1 translation in non-irradiated cells was elF4G1-dependent but DAP5-independent. (B-D) $48 \mathrm{~h}$ after electroporation, cells were irradiated with $10 \mathrm{~Gy}$. (B) Cells were lysed $24 \mathrm{~h}$ after IR. Silencing of elF4G1 or DAP5 had no effect on radiation-induced Mcl-1 decline. Dissipation of the mitochondrial membrane potential $\left(\Delta \psi_{\mathrm{m}}\right.$ low, C) and DNA fragmentation (sub G1, D) were analyzed by flow cytometry $24 \mathrm{~h}$ and $48 \mathrm{~h}$ after IR, respectively. Slightly enhanced $\Delta \psi \mathrm{m}$ dissipation and DNA fragmentation was observed when both, elF4G1 and DAP5, were silenced at the same time. Flow cytometric data shows mean values \pm S.D. $(n=3)$, ${ }^{* *}$ indicates $p<0.001$.

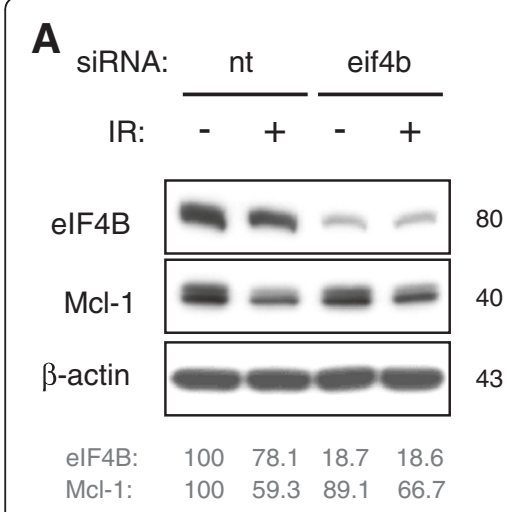

B

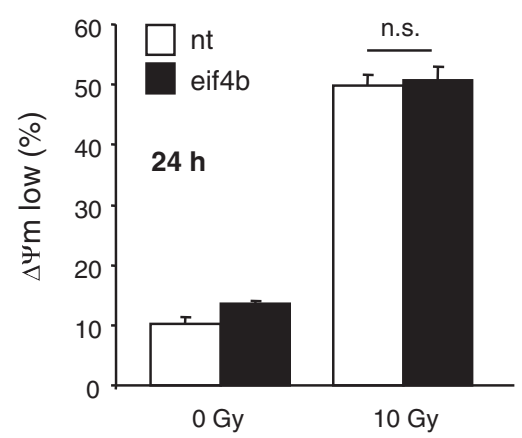

C

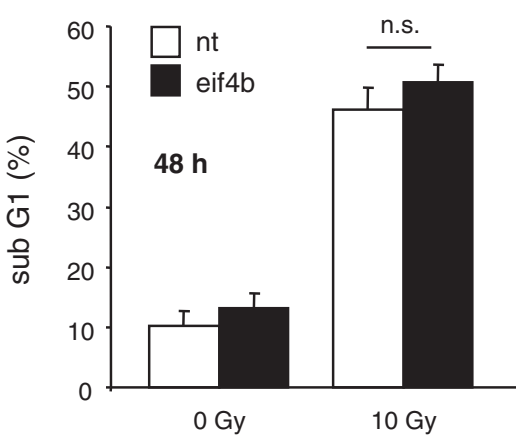

Figure 5 Silencing of elF4B did not change radiation-induced reduction of $\mathbf{M c l}-1$ and apoptosis induction. Jurkat cells were transfected with $1 \mu \mathrm{M}$ eif4b siRNA by electroporation. 2 days later, cells were irradiated with $10 \mathrm{~Gy}$. (A) Lysates were made $24 \mathrm{~h}$ after IR. elF4B and Mcl-1 levels were analyzed by densitometry and normalized to the respective levels of non-irradiated cells transfected with non-targeting siRNA. Dissipation of mitochondrial membrane potential $(\Delta \psi \mathrm{m}$ low, B) and DNA fragmentation (sub G1, C) were analyzed by flow cytometry $24 \mathrm{~h}$ and $48 \mathrm{~h}$ after IR, respectively. Silencing of elF4B had no impact on IR-induced Mcl-1 decline and apoptosis. Flow cytometric data shows mean values \pm S.D. $(n=3)$, n.s. indicates no significance ( $p>0.05)$. 


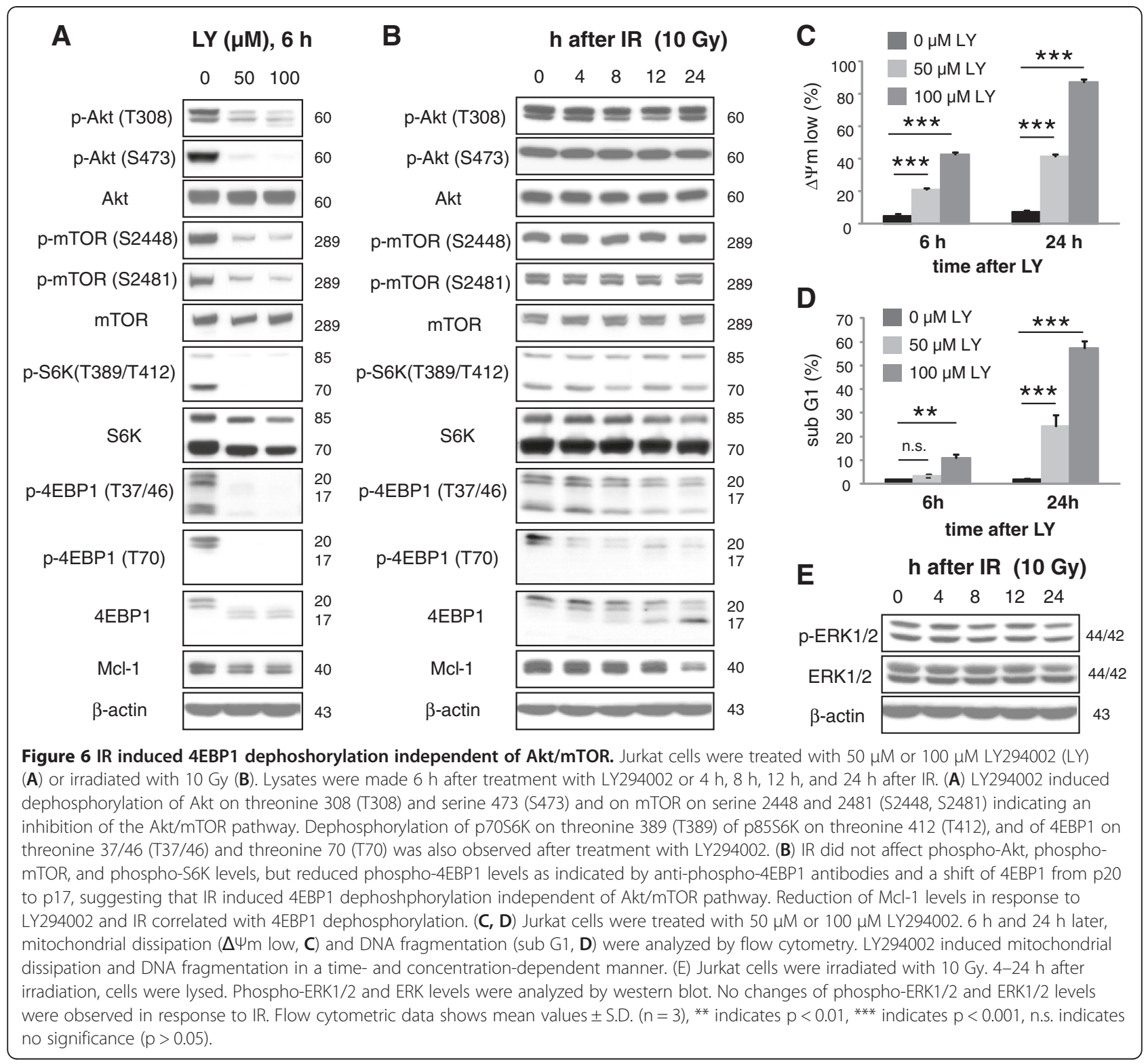

IR-induced cleavage of eIF4G1, eIF4B, eIF3A, and DAP5 coincided with disassembly of the cap-/eIF4G1-dependent and IRES-/DAP5-dependent initiation complex in Jurkat cells. Thus, a switch from cap-/eIF4G1-dependent to IRES-/DAP5-dependent translation, as suggested before $[6,24]$, was very unlikely. We conclude that the caspasedependent cleavage of the eIFs mentioned above resulted in reduced cap- and DAP5-dependent translational initiation. Moreover, the ability to cleave the eIFs might also be responsible for the high toxicity of Jurkat cells to IR. Interestingly, the polyclonal antibody used to detect eIF4G1 should also have recognized eIF4G3/eIF4GII, a protein of $175 \mathrm{kDa}$ homologue to eIF4G1. The failure to detect eIF4G2 suggests that Jurkat cells do not express this eIF4G member.
In addition to caspase-dependent regulation, caspaseindependent regulation of cap-dependent translation was observed in irradiated Jurkat cells. This mechanism involved dephosphorylation of 4EBP1 and enhanced association of this translational inhibitor with the capbinding eIF4E. Previous studies have shown that 4EBP1 was also a central regulator of cap-dependent translation in irradiated breast cancer cells [14]. Moreover, high phospho-4EBP1 levels correlated with grade and malignancy in breast tumors [25]. Phosphorylation of 4EBP1 is regulated by the Akt/mTOR pathway [2,13]. Inhibition of the Akt/mTOR pathway reduces cell survival [26]. Blocking the pathway by LY294002 in Jurkat cells resulted in dephosphorylation of 4EBP1 and S6K, implying a translational inhibition through binding of 4EBP1 to eIF4E and 


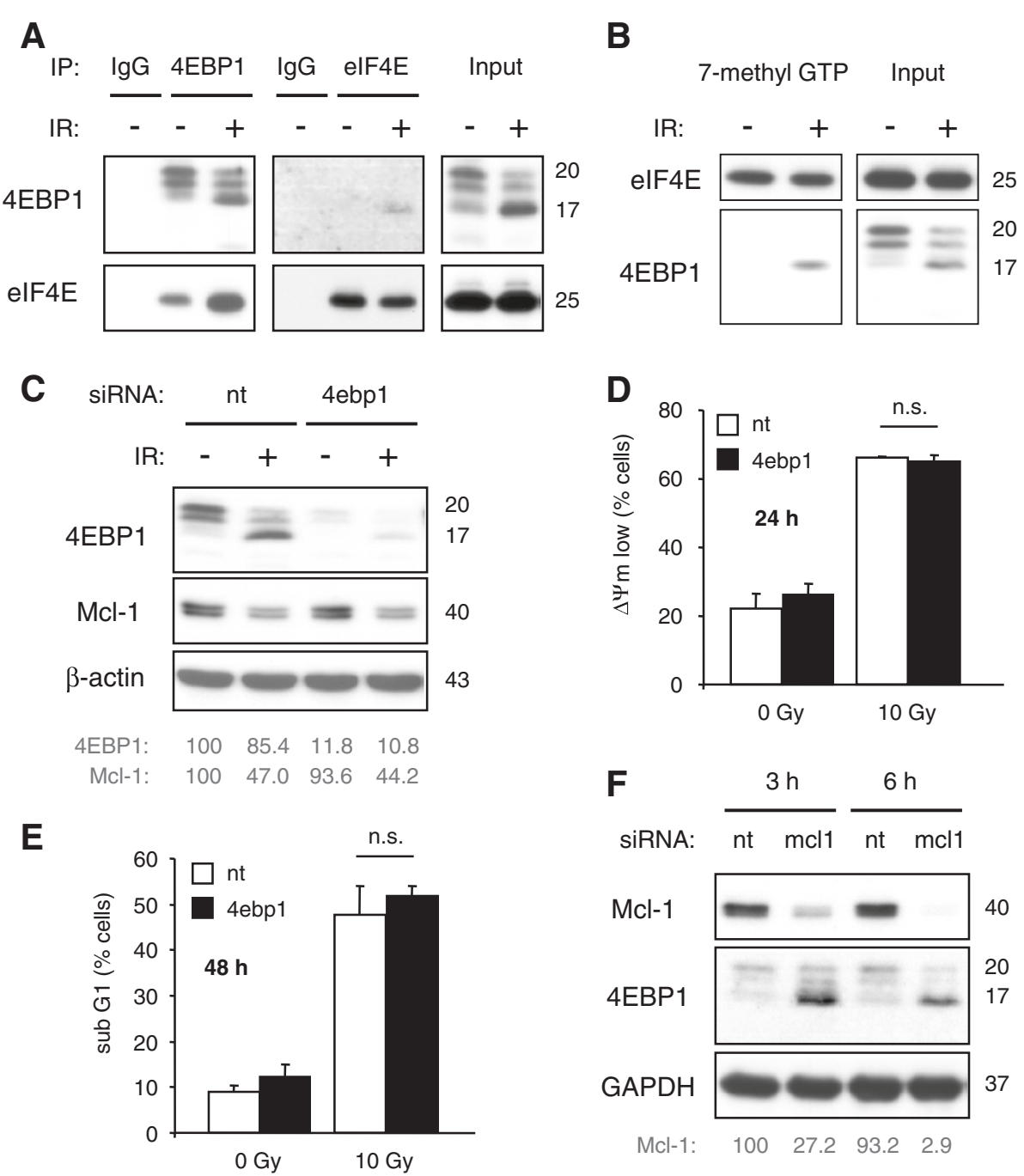

Figure 7 Radiation-induced Mcl-1 decline and apoptosis was not affected by silencing of 4EBP1. (A, B) Jurkat cells were irradiated with $10 \mathrm{~Gy}$. (A) $24 \mathrm{~h}$ after IR cells were lysed and immunoprecipitation was performed using antibodies against 4EBP1 or elF4E. As negative controls, isotype-matched antibodies ( $\mathrm{lgG}$ ) were used. Equal input was verified by western blot. Interaction of 4EBP1 with elF4E was enhanced in irradiated cells. (B) $24 \mathrm{~h}$ after irradiation, cells were lysed and and a pull-down assay was made using 7-methyl GTP agarose. 4EBP1 with elF4E bound to 7-methyl GTP cap. (C-E) Jurkat cells were transfected with $1 \mu \mathrm{M}$ 4ebp1 siRNA or non-targeting (nt) siRNA by electroporation. $48 \mathrm{~h}$ later, cells were irradiated with $10 \mathrm{~Gy}$. (C) $24 \mathrm{~h}$ after irradiation, cells were lysed. 4EBP1 and Mcl-1 protein levels were analyzed by densitometry and normalized to the respective levels in non-irradiated cells transfected with non-targeting siRNA. Silencing of 4EBP1 had hardly any effect on Mcl-1 protein levels. Dissipation of the mitochondrial membrane potential $(\Delta \psi \mathrm{m}$ low, D) and DNA fragmentation (sub G1, E) were analyzed by flow cytometry $24 \mathrm{~h}$ and $48 \mathrm{~h}$ after IR, respectively. (F) Jurkat cells were transfected with $250 \mathrm{nM}$ mcl1 siRNA. Lysates were made $3 \mathrm{~h}$ and $6 \mathrm{~h}$ after electroporation. Mcl-1 protein levels were analyzed by densitometry and normalized to the Mcl-1 level in lysates made $3 \mathrm{~h}$ after transfection with non-targeting siRNA. Down-regulation of $\mathrm{MCl}-1$ by siRNA resulted in a rapid dephosphorylation of $4 \mathrm{EBP} 1$ which was indicated by the shift to faster migrating p17 band. Flow cytometric data show mean values \pm S.D. $(n=3)$, n.s. indicates no significance $(p>0.05)$.

inhibition of S6K. In addition, LY294002 caused a descrease of Mcl-1 level and apoptosis induction. Surprisingly, IR induced dephosphorylation of 4EBP1 although Akt and mTOR remained active, as the phosphorylation state of both kinases indicated. Thus, 4EBP1 dephosphorylation and Mcl-1 decline did not result from Akt/mTOR inhibition. Probably, IR enhanced phosphatase activity leading to increased dephosphorylation of 4EBP1. The phosphatase responsible for the process has not been identified, yet. However, the phosphatase might be regulated independent of caspase-activation, since 4EBP1 was dephosphorylated even in cells treated with the pan-caspase inhibitor zVAD-fmk.

Interestingly, treatment with calyculin $\mathrm{A}$, the unspecific inhibitor of Ser/Thr protein phosphatase (PP) 1 and 2 family, resulted in an accumulation of a phosphorylated high molecular weight form of 4EBP1 in Jurkat cells [27]. Apparently, phosphorylation of 4EBP1 not only regulates 
its association with eIF4E but also targets the protein for poly-ubiquitylation and degradation via proteasome. However, we could not test the effect of calyculin A on IRinduced 4EBP1 dephosphorylation in Jurkat cells due to its rapid cell death induction (unpublished observation).

We focused our research on 4EBP1, one of three members of the 4EBP family. Since the phosphorylation sites are homologues, we expect a similar regulation of the other two related proteins. However, we examined neither the expression not the phosphorylation state of 4EBP2 and 4EBP3 in Jurkat cells. Thus, we cannot exclude a different regulation of the other $4 \mathrm{EBP}$ members leaving open the possibility that alternative regulation of protein translation by $4 \mathrm{EBP} 2$ and $4 \mathrm{EBP} 3$ occurred in irradiated cells. Apart from that, IR resulted in 4EBP1 dephosphorylation without affecting S6K in Jurkat cells suggesting an additional regulation of protein translation. A recent publication indicates that S6K is not dephosphorylated in response to Akt inhibitors when the extracellular regulated kinase (ERK) $1 / 2$ pathway is activated [13]. A persistent ERK $1 / 2$ activation probably contributed to the ongoing phosphorylation of S6K in irradiated Jurkat cells.

Inhibition of translation causes a rapid reduction of shortlived proteins. For example, c-Myc, cyclin D1 and Mcl-1 were quickly down-regulated in lymphoma cells when capdependent translation was blocked [28]. Accordingly,

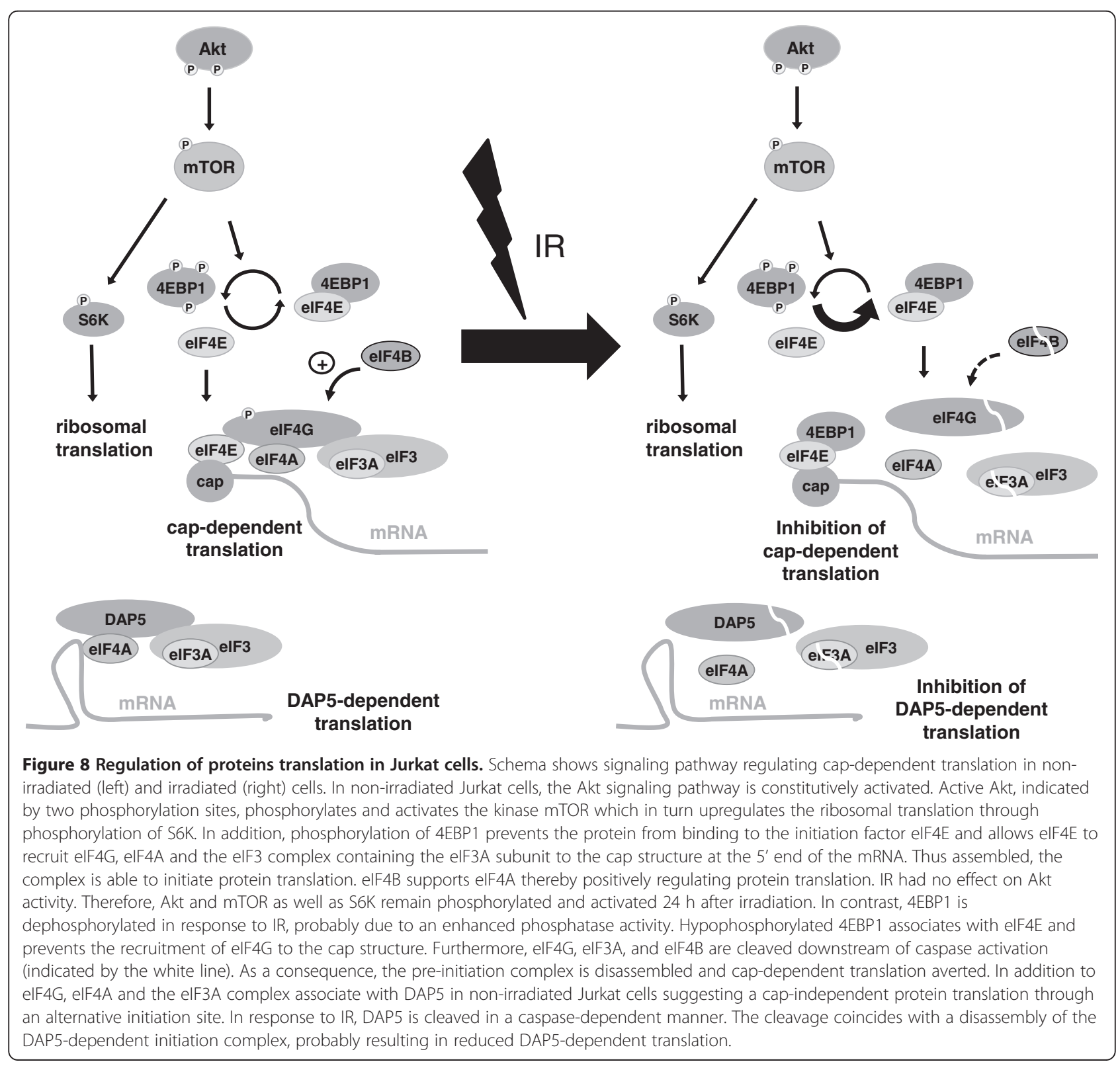


stimulation of cap-dependent translation by PP2A inhibitor okadaic acid or PP2A knock-down increased levels of cMyc and Mcl-1 in human lung cancer cells [29]. Failure to reduce $\mathrm{Mcl}-1$ levels resulted in enhanced survival and radioresistance [30].

We detected a rapid Mcl-1 decline in Jurkat cells treated with the translational inhibitor CHX. CHX-induced Mcl-1 decline was also observed in glioblastoma and cervical cancer cells [9]. Moreover, previous studies have shown that Jurkat cell survival depended on Mcl-1 expression [7,11]. Depletion of Mcl-1 by siRNA resulted in apoptosis induction. Mcl-1 protein levels might also be decreased by caspase-dependent cleavage [31,32]. However, inhibition of caspases did not prevent IR-induced down-regulation of Mcl-1 and 4EBP1 dephosphorylation in Jurkat cells suggesting a caspase-independent regulation of Mcl-1 levels in response to IR. The coinciding caspase-independent Mcl-1 decline and translational inhibition due to dephosphorylated 4EBP1 rather suggests that IR-induced inhibition of cap-dependent translation caused depletion of Mcl-1. Indeed, knock-down of eIF4G1 by siRNA decreased Mcl-1 levels in Jurkat cells but, surprisingly, did not affect IRinduced Mcl-1 decline. In addition, down-regulation of eIF4B or DAP5 by siRNA affected Mcl-1 protein level neither in non-irradiated nor in irradiated cells. Our results suggest that the IR-induced Mcl-1 decline was not caused by inhibition of cap-dependent or IRES/DAP5-dependent translation although Mcl-1 expression was translationally controlled by eIF4G1 in non-irradiated, healthy Jurkat cells. Furthermore, silencing of eIF4B, eIF4G1, or DAP5 had no effect or, in case of simultanous eIF4G1 and DAP5 silencing, only very modest effects on radiation-induced apoptosis leaving the question about the biological relevance of these radiation effects open.

Recently, further mechanisms controlling Mcl-1 stability have been published. Mcl-1 ubiquitin ligase E3 (Mule) and the Skip/Cullin/F-Box ligase complex containing $\beta$ transducin repeat-containing protein $(\beta-\mathrm{TrCP})$ or $\mathrm{FBW} 7$ were able to ubiquitylate Mcl-1 and target the protein for proteosomal degradation [33-36]. In contrast, the deubiquitinase USP9x prevented Mcl-1 degradation and stabilized Mcl-1 levels by removing the poly-ubiquitin chain [37]. Thus, Mcl-1 levels might be lowered by enhanced ubiquitylation or reduced deubiquitylation. Indeed, the accelerated Mcl-1 degradation in irradiated cells shown in Figure 3 and a previous publication [11] supports a posttranslational regulation of Mcl-1. Recently, we have demonstrated that USP9 $\mathrm{x}$ was activated in a Jurkat subclone, but not in the parental cell line, in response to IR [11]. The USP9 $x$ activation resulted in enhanced Mcl-1 deubiquitination and an increased resistance to IR-induced apoptosis in this specific clone. It remains to be shown whether IR also activates Mcl-1-specific ubiquitin ligases to facilitate Mcl-1 ubiquitylation and proteasomal degradation in Jurkat cells.

\section{Conclusions}

In summary, our results indicate that IR inhibited cap-/ eIF4G1-dependent and DAP5-dependent translation in Jurkat cells. The mechanism leading to translational inhibition in response to IR involved caspase-dependent cleavage of eIF4G1, eIF4B, eIF3A, and DAP5 as well as caspase-independent dephosphorylation of 4EBP1. IRinduced decrease of phosphorylated 4EBP1 did not result from inhibition of Akt and mTOR but probably from increased phosphatase activity. The effects of IR on protein translation are summarized in Figure 8. We conclude that IR controled protein translation at different levels. However, decline of the short-lived, anti-apoptotic Mcl-1 in response to irradiation was not caused by inhibition of protein translation.

\section{Abbreviations}

Mcl-1: Myeloid cell leukemia sequence 1; IR: lonizing radiation; elF: Eukaryotic initiation factor; DAP5: Death associated protein 5; 4EBP1: elF4E binding protein 1; IRES: Internal ribosome entry site; mTOR: Mammalian target of rapamycin; ERK1/2: Extracellular regulated kinase 1/2; CHX: Cycloheximide.

\section{Competing interests}

The authors declare that they have no competing interests.

\section{Authors' contributions}

JR designed the study. DT and JR, supported by LB and SMH, acquired, analyzed, and interpreted data. JR drafted and revised the manuscript. All authors read and approved the final manuscript.

\section{Acknowledgments}

The work was supported by grants from the German Research Foundation DFG (RU 1641/1-1) to JR and from the Wilhelm Sander Stiftung (2011.083.1) to $\mathrm{SMH}$. We thank Dr. Frank Grünebach for providing the electroporation device and Heidrun Faltin for technical assistance.

Received: 20 August 2012 Accepted: 3 February 2013

Published: 13 February 2013

\section{References}

1. Stoneley M, Willis AE: Cellular internal ribosome entry segments: structures, trans-acting factors and regulation of gene expression. Oncogene 2004, 23:3200-3207.

2. Hidalgo M, Rowinsky EK: The rapamycin-sensitive signal transduction pathway as a target for cancer therapy. Oncogene 2000, 19:6680-6686.

3. Marcotrigiano J, Gingras AC, Sonenberg N, Burley SK: Cap-dependent translation initiation in eukaryotes is regulated by a molecular mimic of elF4G. Mol Cell 1999, 3:707-716.

4. Powley IR, Kondrashov A, Young LA, Dobbyn HC, Hill K, Cannell IG, Stoneley $\mathrm{M}$, Kong YW, Cotes JA, Smith GC, et al: Translational reprogramming following UVB irradiation is mediated by DNA-PKcs and allows selective recruitment to the polysomes of mRNAs encoding DNA repair enzymes. Genes Dev 2009, 23:1207-1220.

5. Spriggs KA, Bushell M, Willis AE: Translational regulation of gene expression during conditions of cell stress. Mol Cell 2010, 40:228-237.

6. Marash L, Kimchi A: DAP5 and IRES-mediated translation during programmed cell death. Cell Death Differ 2005, 12:554-562.

7. Rudner J, Elsaesser SJ, Muller AC, Belka C, Jendrossek V: Differential effects of anti-apoptotic $\mathrm{BCl}-2$ family members $\mathrm{Mcl}-1, \mathrm{BCl}-2$, and $\mathrm{BCl}-\mathrm{xL}$ on celecoxib-induced apoptosis. Biochem Pharmacol 2010, 79:10-20.

8. Wang R, Xia L, Gabrilove J, Waxman S, Jing Y: Downregulation of Mcl-1 through GSK-3beta activation contributes to arsenic trioxide-induced apoptosis in acute myeloid leukemia cells. In Leukemia: official journal of the Leukemia Society of America. UK: Leukemia Research Fund; 2012.

9. Adams KW, Cooper GM: Rapid turnover of mcl-1 couples translation to cell survival and apoptosis. J Biol Chem 2007, 282:6192-6200. 
10. Huber S, Oelsner M, Decker T, Zum Buschenfelde CM, Wagner M, Lutzny G, Kuhnt T, Schmidt B, Oostendorp RA, Peschel C, Ringshausen I: Sorafenib induces cell death in chronic lymphocytic leukemia by translational downregulation of Mcl-1. In Leukemia: official journal of the Leukemia Society of America. UK: Leukemia Research Fund; 2011.

11. Trivigno D, Essmann F, Huber SM, Rudner J: Deubiquitinase USP9x confers radioresistance through stabilization of Mcl-1. Neoplasia (New York, NY) 2012, 14:893-904

12. Henis-Korenblit S, Shani G, Sines T, Marash L, Shohat G, Kimchi A: The caspase-cleaved DAP5 protein supports internal ribosome entry sitemediated translation of death proteins. Proc Natl Acad Sci U S A 2002, 99:5400-5405.

13. She QB, Halilovic E, Ye Q, Zhen W, Shirasawa S, Sasazuki T, Solit DB, Rosen $\mathrm{N}$ : 4E-BP1 is a key effector of the oncogenic activation of the AKT and ERK signaling pathways that integrates their function in tumors. Cancer Cell 2010, 18:39-51.

14. Braunstein S, Badura ML, Xi Q, Formenti SC, Schneider RJ: Regulation of protein synthesis by ionizing radiation. Mol Cell Biol 2009, 29:5645-5656.

15. Lee T, Pelletier J: Eukaryotic initiation factor 4F: a vulnerability of tumor cells. Future Med Chem 2012, 4:19-31.

16. Shahbazian D, Parsyan A, Petroulakis E, Hershey J, Sonenberg N: elF4B controls survival and proliferation and is regulated by proto-oncogenic signaling pathways. Cell Cycle 2010, 9:4106-4109.

17. Zhang L, Pan $X$, Hershey JW: Individual overexpression of five subunits of human translation initiation factor elF3 promotes malignant transformation of immortal fibroblast cells. J Biol Chem 2007, 282:5790-5800.

18. Liu RY, Dong Z, Liu J, Yin JY, Zhou L, Wu X, Yang Y, Mo W, Huang W, Khoo SK, et al: Role of elF3a in regulating cisplatin sensitivity and in translational control of nucleotide excision repair of nasopharyngeal carcinoma. Oncogene 2011, .

19. Badura M, Braunstein S, Zavadil J, Schneider RJ: DNA damage and elF4G1 in breast cancer cells reprogram translation for survival and DNA repair mRNAs. Proc Natl Acad Sci U S A 2012, 109:18767-18772.

20. Marissen WE, Lloyd RE: Eukaryotic translation initiation factor $4 \mathrm{G}$ is targeted for proteolytic cleavage by caspase 3 during inhibition of translation in apoptotic cells. Mol Cell Biol 1998, 18:7565-7574.

21. Bushell M, Wood W, Carpenter G, Pain VM, Morley SJ, Clemens MJ: Disruption of the interaction of mammalian protein synthesis eukaryotic initiation factor $4 \mathrm{~B}$ with the poly $(\mathrm{A})$-binding protein by caspase- and viral protease-mediated cleavages. J Biol Chem 2001, 276:23922-23928.

22. Clemens MJ, Bushell M, Jeffrey IW, Pain VM, Morley SJ: Translation initiation factor modifications and the regulation of protein synthesis in apoptotic cells. Cell Death Differ 2000, 7:603-615.

23. Fraser CS, Lee JY, Mayeur GL, Bushell M, Doudna JA, Hershey JW: The j-subunit of human translation initiation factor elF3 is required for the stable binding of elF3 and its subcomplexes to $40 \mathrm{~S}$ ribosomal subunits in vitro. J Biol Chem 2004, 279:8946-8956.

24. Marash L, Liberman N, Henis-Korenblit S, Sivan G, Reem E, Elroy-Stein O, Kimchi A: DAP5 promotes cap-independent translation of $\mathrm{BCl}-2$ and CDK1 to facilitate cell survival during mitosis. Mol Cell 2008, 30:447-459.

25. Rojo F, Najera L, Lirola J, Jimenez J, Guzman M, Sabadell MD, Baselga J, Ramon y Cajal S: 4E-binding protein 1, a cell signaling hallmark in breast cancer that correlates with pathologic grade and prognosis. Clin Cancer Res 2007, 13:81-89.

26. Rudner J, Ruiner CE, Handrick R, Eibl HJ, Belka C, Jendrossek V: The Aktinhibitor Erufosine induces apoptotic cell death in prostate cancer cells and increases the short term effects of ionizing radiation. Radiat Oncol 2010, 5:108

27. Elia A, Constantinou C, Clemens MJ: Effects of protein phosphorylation on ubiquitination and stability of the translational inhibitor protein 4E-BP1. Oncogene 2008, 27:811-822.

28. Schatz JH, Oricchio E, Wolfe AL, Jiang M, Linkov I, Maragulia J, Shi W, Zhang Z, Rajasekhar VK, Pagano NC, et al: Targeting cap-dependent translation blocks converging survival signals by AKT and PIM kinases in lymphoma. J Exp Med 2011, 208:1799-1807

29. Li Y, Yue P, Deng X, Ueda T, Fukunaga R, Khuri FR, Sun SY: Protein phosphatase $2 \mathrm{~A}$ negatively regulates eukaryotic initiation factor $4 \mathrm{E}$ phosphorylation and elF4F assembly through direct dephosphorylation of Mnk and elF4E. Neoplasia (New York, NY) 2010, 12:848-855.
30. Skvara $H$, Thallinger $C$, Wacheck $V$, Monia BP, Pehamberger $H$, Jansen $B$, Selzer E: Mcl-1 blocks radiation-induced apoptosis and inhibits clonogenic cell death. Anticancer Res 2005, 25:2697-2703.

31. Snowden RT, Sun XM, Dyer MJ, Cohen GM: Bisindolylmaleimide IX is a potent inducer of apoptosis in chronic lymphocytic leukaemic cells and activates cleavage of Mcl-1. Leukemia: official journal of the Leukemia Society of America, Leukemia Research Fund, UK 2003, 17:1981-1989.

32. Weng C, Li Y, Xu D, Shi Y, Tang H: Specific cleavage of Mcl-1 by caspase-3 in tumor necrosis factor-related apoptosis-inducing ligand (TRAIL)induced apoptosis in Jurkat leukemia T cells. J Biol Chem 2005, 280:10491-10500.

33. Ding Q, He X, Hsu JM, Xia W, Chen CT, Li LY, Lee DF, Liu JC, Zhong Q Wang $X$, Hung MC: Degradation of Mcl-1 by beta-TrCP mediates glycogen synthase kinase 3-induced tumor suppression and chemosensitization. Mol Cell Biol 2007, 27:4006-4017.

34. Inuzuka H, Shaik S, Onoyama I, Gao D, Tseng A, Maser RS, Zhai B, Wan L, Gutierrez A, Lau AW, et al: SCF(FBW7) regulates cellular apoptosis by targeting MCL1 for ubiquitylation and destruction. Nature 2011, 471:104-109.

35. Wertz IE, Kusam S, Lam C, Okamoto T, Sandoval W, Anderson DJ, Helgason E, Ernst JA, Eby M, Liu J, et al: Sensitivity to antitubulin chemotherapeutics is regulated by MCL1 and FBW7. Nature 2011, 471:110-114.

36. Zhong Q, Gao W, Du F, Wang X: Mule/ARF-BP1, a BH3-only E3 ubiquitin ligase, catalyzes the polyubiquitination of $\mathrm{Mcl}-1$ and regulates apoptosis. Cell 2005, 121:1085-1095.

37. Schwickart M, Huang X, Lill JR, Liu J, Ferrando R, French DM, Maecker H, O'Rourke K, Bazan F, Eastham-Anderson J, et al: Deubiquitinase USP9X stabilizes MCL1 and promotes tumour cell survival. Nature 2010, 463:103-107.

doi:10.1186/1748-717X-8-35

Cite this article as: Trivigno et al:: Regulation of protein translation initiation in response to ionizing radiation. Radiation Oncology 2013 8:35.

\section{Submit your next manuscript to BioMed Central and take full advantage of:}

- Convenient online submission

- Thorough peer review

- No space constraints or color figure charges

- Immediate publication on acceptance

- Inclusion in PubMed, CAS, Scopus and Google Scholar

- Research which is freely available for redistribution 